\title{
A Comparison of Face-to-Face Versus Online Instruction in the Correct Pronunciation of Anatomical Terms in Communication Sciences and Disorders. An Initial Investigation
}

Ann L. Cralidis

Longwood University, cralidisal@longwood.edu

Shannon W. Salley

Longwood University, salleysw@longwood.edu

DOI: https://doi.org/10.30707/TLCSD4.1/XPYX7774

Follow this and additional works at: https://ir.library.illinoisstate.edu/tlcsd

Part of the Speech Pathology and Audiology Commons

\section{Recommended Citation}

Cralidis, Ann L. and Salley, Shannon W. (2020) "A Comparison of Face-to-Face Versus Online Instruction in the Correct Pronunciation of Anatomical Terms in Communication Sciences and Disorders. An Initial Investigation," Teaching and Learning in Communication Sciences \& Disorders: Vol. 4: Iss. 1, Article 6. DOI: https://doi.org/10.30707/TLCSD4.1/XPYX7774

Available at: https://ir.library.illinoisstate.edu/tlcsd/vol4/iss1/6

This Pilot Studies is brought to you for free and open access by ISU ReD: Research and eData. It has been accepted for inclusion in Teaching and Learning in Communication Sciences \& Disorders by an authorized editor of ISU ReD: Research and eData. For more information, please contact ISUReD@ilstu.edu. 


\title{
A Comparison of Face-to-Face Versus Online Instruction in the Correct Pronunciation of Anatomical Terms in Communication Sciences and Disorders. An Initial Investigation
}

\begin{abstract}
Accurate pronunciation of anatomical terms in the clinical practice of speech-language pathology (SLP) and audiology (AUD) enables a clinician to express and comprehend a conversation with peers and other professionals. It is also an important component of ensuring patient safety and in providing quality, patient-centered care. To date, no studies have explored whether differences may exist between the pronunciation skills of students who elect to complete a human anatomy and physiology course online versus in a face-to-face (FTF) format. This pilot study explored the ability of 98 undergraduate student participants to correctly pronounce 20 identical key terms that were a part of the course Anatomy and Physiology of the Speech and Hearing Mechanism. Students were enrolled in either an online or a FTF format of this course. Student participants were also asked to self-rate their perceived ability to pronounce these terms correctly using a Likert-type rating scale. The results indicated that students enrolled in the FTF format produced a significantly greater percentage of correct terms and rated their pronunciation ability significantly higher compared to those enrolled online. Performance of both groups was positively correlated to the self-ratings of pronunciation accuracy. These results suggest that an Internet-based, multimedia teaching method that incorporates tools for improving the pronunciation skills of students who complete a human anatomy and physiology course is warranted.
\end{abstract}




\section{Introduction}

Undergraduate students who are enrolled in a Communication Sciences and Disorders (CSD) program must acquire a vast quantity of specialized vocabulary across a number of courses within the major. One particular course in which students are challenged with this task is in a human anatomy and physiology course that focuses on acquiring anatomical terms related to the professional practice of speech-language pathology (SLP) or audiology (AUD). This type of course is often mandatory for degree completion. An essential component of this course is predicated upon the ability to pronounce terminology correctly and precisely. Accurate pronunciation skills enable one to express and comprehend a conversation with colleagues and other professionals, ensure patient safety, and provide quality, patient-centered services. As such, costly errors may occur when terms that are similar to one another are not pronounced correctly. To illustrate, changing the term malleus to malleolus changes the name of a bone within the middle ear to the name of a bony protuberance in the ankle.

The ubiquitous availability of the Internet has created options for student learning beyond the traditional brick-and-mortar classroom. It is estimated that approximately 32 percent of all students in higher education take at least one course online (Allen \& Seaman, 2013). Certainly, the Internet has become a critical part of daily life that influences the way in which students learn and teachers teach (Lowerison, Schater, Schmid, \& Abrami, 2006). However, the use of technology tools alone does not always equate to effective teaching or to adequate mastery of the material (Gopal et al., 2010). Some investigations have posited that technology that is infused with a number of online tools may help to enhance teaching methods, permit course objectives to be met, and allow students to enrich and increase their learning (Cuthrell, 2007; Gopal et al., 2010; Okojie, Olinzock, \& Boulder, 2006; Schacter, 1999). Yet, a cornerstone of teaching and learning in an online format is the ability to select the most appropriate technological tools so that the mastery of key course content can occur (Duffy \& Mcdonald, 2008; Gopal et al., 2010). There is a vast body of literature (Casotti, Rieser-Danner, \& Knabb, 2008; Chaplin \& Manske, 2005; Perry, Kuehn, \& Langlois, 2007; Rissing \& Cogan, 2009) that has explored ways to improve online instruction in general. However, for science-based courses, only a few studies have explored the utility of web-based technology as a means to enhance student learning in an online human anatomy and physiology course (Gopal et al., 2010; Kuyatt \& Baker, 2014; Limpfaach, Bazrafshan, Turner, \& Monaghan, 2008). To illustrate, Gopal and colleagues (2010) explored the utility of the Cardiovascular (CS) website, which was developed specifically by the researchers for this investigation, to assist 165 undergraduate student participants who were enrolled in an online anatomy and physiology lab for non-biology majors such as nursing and community health. The purpose of the website was to assist students in mastering reading, spelling, writing, and pronunciation skills. The experimental group $(n=80)$ was given access to the website, while the control group was not. The Pronunciation Center (PC) and the Spelling Bee (SB) were dedicated portals within the CS website where participants could hear the pronunciation of key terminology and then spell the words for practice. The data from both groups was analyzed in light of their overall performance on an examination, although it is unclear whether assessment of pronunciation skills was specifically included. The results indicated that participants enrolled in the experimental group had higher mean scores when compared to the control group suggesting that the CS website may augment student learning in an anatomy and physiology lab. In addition, the researchers noted that the inclusion of a myriad 
of online technological tools, including videos, practice tests, and additional web resources, may have also influenced student performance.

In a similar study, Limpach and colleagues (2008) investigated the efficacy of a human anatomy course that was taught online and in a face-to-face format (FTF) over a consecutive period of time from 2003-2006. All students were enrolled in a doctor of pharmacy program. Approximately 100 student participants completed the FTF course each year, whereas approximately 50 student participants were enrolled online during the same time period. The FTF environment employed a lecture and discussion format that included participant access to a "word of the week" activity that asked them to pronounce and spell various medical terms. The distance learning format used recorded lectures and instructor-led live text- and voice-based discussions, as well as the same "word of the week" activity that FTF participants completed. Participant performance was analyzed relative to their final course percentage grades and letter grades. The results suggested that student participants enrolled in the online course performed significantly better, as evidenced by both their final letter and percentage grades, when compared to those enrolled in a FTF format, for the year 2006 only. There were no significant differences observed between the groups for the years 2003-2005. It is unknown whether the investigators asked participants to complete the "word of the week" activity for a grade and thus, whether this particular task may have influenced the overall outcome from this study. However, the findings suggest that students may benefit from a guided pronunciation task. In addition, the results corroborate the findings obtained by Gopal and colleagues (2010) in that the recruitment of a variety of Internet-based technology may also optimize and increase student learning.

More recently, Saltarelli, Roseth, and Saltarelli (2014) compared the performance of 233 undergraduate students, approximately $20 \%$ of whom were enrolled in an allied health program, who were randomly assigned to complete either an online or FTF human anatomy and physiology course. Specifically, student participants in the FTF format completed assignments using a human cadaver while those enrolled online used Anatomy and Physiology Revealed (APR) (Schneider, Morse, Bennett-Clarke, \& Hankin, n.d.), a multimedia simulation, including audio pronunciations, imaging, and three-dimensional animations, of a human cadaver. Participant data was analyzed relative to student performance on tasks of identification and identification/explanation that were a part of an examination. An example of an identification question asked participants to identify a blood vessel that was marked by a numbered pin. An example of an identification/explanation question asked participants to name the organ that a numbered, pinned blood vessel supplied. The results indicated that participants who used APR were at a significant disadvantage in their ability to identify and explain anatomical structures on a human cadaver when compared to students enrolled in a FTF lab. However, it is unknown whether student participants received a reduction in grade if a term was pronounced incorrectly. Together, these investigations support previous research (Borsook \& Higginbotham-Wheat, 1991; Bulger, Mohr, \& Walls, 2002; Woodrow, Mayer-Smith, \& Pedretti, 2000) that has found that online learning is optimized when students are actively engaged via the use of multimedia, including the use of pronunciation and spelling tasks, imaging, videos, audiotaped lectures, and discussions with peers and instructors.

However, these studies only examined student performance, regardless of instructional format, holistically. Correct pronunciation of professional terminology is critical for patient safety and 
effective communication between other professionals, colleagues, and the public. The inability to accurately pronounce key terms may result in loss of professional credibility and denial of payment for services rendered. The purpose of this investigation was to examine whether differences exist in pronunciation accuracy between students who complete an online human anatomy and physiology course of the speech and hearing mechanism and those who elect to complete such a course online. The investigation further explored the relationship between students' self-rated ability to pronounce the terms correctly and their overall accuracy score.

\section{Methods}

Forty-eight online and $50 \mathrm{FTF}$ student participants volunteered to participate in this initial investigation after IRB approval was obtained. All student participants met the following inclusionary criteria: 1) enrollment in either the online or FTF course format of Anatomy and Physiology of the Speech and Hearing Mechanisms; 2) speakers of standard English; 3) no selfreported history of learning or developmental disability; 4) no self-reported presence of any motor speech disorder; and 5) normal or corrected hearing. The FTF course is a part of the undergraduate CSD curriculum and is mandatory for degree completion. The FTF course is taught twice per week for 75 minutes per class period. The online course is offered through the Longwood University SLP Online Program, a continuing education program that is offered to those students who want to take the CSD undergraduate prerequisite courses in order to apply to a graduate program in CSD. The online course is entirely self-paced. The course materials for the online and FTF format courses were identical except for the inclusion of discussion boards in the online format only. All course materials for both course formats were made available on Canvas TM, an online learning management platform. The first author, a full-time faculty member at Longwood University who has eight years of teaching experience and who holds a terminal degree in CSD, was the instructor for the online and FTF format classes.

At the conclusion of both courses, all participants were given identical word lists, created by the investigators specifically for this study that contained 20 key-content terms that were used during both courses. These terms are presented in the Appendix. Key terms were selected if they met the following inclusionary criteria: 1) each term was uniquely and specifically related to the anatomy and physiology of the speech and hearing mechanism; 2) each term was used at least three times in both course formats; and 3) each term had only one acceptable, standard pronunciation. First, all participants were instructed to verify their access to and ability to operate one of three, audio recording programs: QuickTime Player TM (Apple, Inc., 1991), Windows Sound Recorder TM (Microsoft, Inc., 2010), or Windows Voice Recorder TM (Microsoft, Inc., 2010). Second, all participants were instructed to begin the audio recording program and to identify whether they were enrolled in either the online or FTF course by reading the most applicable statement prepared by the investigators. All participants were asked to refrain from identifying themselves by name on the recording. Next, participants were asked to pronounce each of the 20 terms, one at a time. Last, all participants were asked to rate, using a Likert-type rating scale, their self-perceived ability to correctly pronounce all of the terms. This Likert rating scale was based on a scale of 1 to 5 , with " 5 " indicating that the participant felt that he/she could correctly pronounce all of the target words and " 1 " indicating that the participant felt that he/she could not correctly pronounce any of the target words. All participants submitted their audio recordings via an anonymous email account to the first author. Those who did not have an anonymous email account were asked to create one using the online service Mailinator 
TM (ManyBrain, Inc., 2007). Prior to beginning this task, all participants were given a written copy of the task instructions and word list.

The scoring of the word terms contained within the audio recordings was completed individually by the investigators. Word terms were scored as either correct or incorrect in pronunciation. Pronunciation of all word terms was verified using the audio and/or phonetic files contained within The Free Dictionary website (Farlex, Inc., 2019), in accordance with the procedure employed by a previous investigation (Gopal et al., 2010). Audio recordings were eliminated if the quality of the recording compromised the ability to accurately score the pronunciations. To establish inter-rater reliability on the scoring procedure, two speech-language pathologists who were certified by the American Speech-Language-Hearing Association (ASHA) and who were blind to the purpose of this study were trained in the scoring method. Interjudge agreement for both raters was established on 20 percent of the data. Interjudge reliability was .90 .

To determine whether the percentage of correct responses for each word differed across the online and FTF groups, cross-tabulations with chi-square procedures were conducted. To determine whether the online and FTF student participants differed in terms of their self-ratings on the Likert-type rating scale and total correct responses, independent $t$-test procedures were conducted. The difference was assessed at a two-tailed alpha of .05 because the direction of the difference was not specified. Prior to conducting the $t$-tests, the two variables were assessed for univariate normality (Kline, 2011). Both variables were distributed normally as their skewness indices fell below three (i.e., skewness index for self-ratings was -1.71 and the index for total score was -2.23) and the kurtosis indices were below 10 (i.e., the kurtosis index for self-ratings was .67 and the index for total score was -1.15$)$. To determine a relationship between the total number of correct pronunciations and self-ratings about performance, Pearson-product moment correlation procedures were conducted.

\section{Results}

The results in Table 1 indicate that the mean total score of total correct pronunciations differed significantly between the online and FTF groups, $t(96)=-4.76, p<.001$. The mean total score of total correct pronunciations for the FTF group only $(M=16.00, S D=3.14)$ was significantly higher than the mean total score of total correct pronunciations for the online group $(M=12.88$, $S D=3.36)$.

In examining performance on specific terms, the investigators found that the percentage of correct pronunciations for the FTF group were only significantly higher than the percentage of correct pronunciations for the online group for the following 10 terms: velar (94\% for FTF vs. $60.4 \%$ for online); foramen (64\% for FTF vs. $31.3 \%$ for online); arytenoid ( $88 \%$ for FTF vs. $56.3 \%$ for online); conchae (56\% for FTF vs. $29.2 \%$ for online); vallecula ( $88 \%$ for FTF vs. $68.8 \%$ for online); labii ( $56 \%$ for FTF vs. $31.3 \%$ for online); platysma ( $80 \%$ for FTF vs. $60.4 \%$ for online); alveolar (90\% for FTF vs. $47.9 \%$ for online); sphenoid (80\% for F TF vs. $60.4 \%$ for online); and musculus uvula ( $98 \%$ for FTF vs. $75 \%$ for online). The results in Table 2 indicate that self-ratings about pronunciation performance also differed significantly between the FTF and online groups, $t(89)=-3.22, p=.002$. The mean self-rating for the FTF group $(M=3.92$, $S D=.57)$ was significantly higher than the mean self-rating for the online group $(M=3.50$, 
$S D=.72$ ). The results indicate that for both the online and FTF groups, self-ratings about performance were positively correlated to mean performance, $r=.62, p<.001$ and $r=.49, p<.001$, respectively.

Table 1

Independent t-test Results for Mean Total Score for Online and FTF Students

\begin{tabular}{llllll}
\hline & $\frac{\text { Online }}{(N=48)}$ & & $\frac{\text { FTF }}{(N=50)}$ & & \\
Variable & $M$ & $S D$ & $M$ & $S D$ & $t$ \\
\hline Total score & 12.88 & 3.36 & 16.00 & 3.14 & 4.76 \\
\hline$p<.001$ & & & & &
\end{tabular}

Table 2

Independent t-test Results for Self-Rating for Online and FTF Students

\begin{tabular}{llllll}
\hline & $\frac{\text { Online }}{(N=48)}$ & & $\frac{\text { FTF }}{(N=50)}$ & & \\
Variable & $M$ & $S D$ & $M$ & $S D$ & $t$ \\
\hline Self-rating & 3.50 & .72 & 3.92 & .57 & -3.22 \\
\hline$p<.01$ & & & & & \\
\hline
\end{tabular}

\section{Discussion}

The purpose of this investigation was to determine whether differences may exist in the ability of student participants, enrolled in either an online or FTF format human anatomy and physiology course, to correctly pronounce a selection of key content terms and to further determine whether participant self-ratings of performance were related to pronunciation outcomes. The findings suggested that student participants enrolled in the FTF course performed significantly better on the pronunciation task, as evidenced by the total number of words correctly pronounced, in comparison to those enrolled in the online format. In examining performance on each individual term, we found that students enrolled in the FTF course again performed significantly better on half of the terms when compared to those enrolled in the online format. Moreover, student 
participants enrolled in the FTF format of the course self-rated their pronunciation skills significantly higher than did those who were enrolled online. However, regardless of group, student participants who correctly pronounced a greater number of terms correctly were more likely to self-rate their performance higher on the Likert-type rating scale.

These findings are in agreement with those observed by Saltarelli and colleagues (2014) who found that students who were enrolled in an online human anatomy course were significantly disadvantaged in their ability to identify and explain key anatomical structures on a human cadaver in comparison to students who were enrolled in a FTF version of the same course. While pronunciation was a component of the task that student participants were asked to complete, it is unknown whether performance on this particular task was included in the final grade calculation. However, the findings of the present investigation are in contrast with those observed by Gopal and colleagues (2010) and Limpach et al. (2008), who found that students who were enrolled in an online human anatomy and physiology course performed significantly better, as evidenced by performance on an examination and final grade, respectively, than did those enrolled in the FTF course. While pronunciation of anatomical terms was a component of overall student performance in these investigations, similar to the method employed by Saltarelli and colleagues (2014), it is unknown whether student performance on this particular task was included in the calculation of course grades.

One observation that may account for the differences obtained in the present investigation and those undertaken previously is the breadth and depth of online tools that were used to enhance student learning in the previous investigations. To illustrate, Gopal et al. (2010) developed a website specifically for their investigation that included an interactive spelling bee and pronunciation corner, practice tests, links to relevant websites, and teacher resource portal. Limpach and colleagues (2008) employed recorded lectures, an interactive Microsoft PowerPoint ${ }^{\circledR}$ presentation that was used for active note taking, a "word of the week" activity, and text- and voice-based discussions. Saltarelli et al. (2014) employed a commerciallyavailable, interactive, multimedia learning system that included high-resolution images and animations. In contrast, the present investigation employed online media and online, web-based resources that primarily required passive participation on the part of student participants. As such, the inclusion of highly-interactive and auditory-based online materials that fully engage the online learner may offer a richer learning experience that may, in turn, improve academic performance.

As previously mentioned, students' ability to accurately pronounce terms related to their professional field impacts their perceived competence among colleagues and clients, allows them to actively participate in professional conversations, and increases overall patient safety. Furthermore, as suggested by Allen and Seaman (2013), more students are participating in online learning as part of their high education programs. Therefore, the importance of facilitating professional vocabulary pronunciation in the online environment cannot be stressed enough, and the results of this study support further research regarding techniques to facilitate pronunciation of anatomical terms in online classes.

It should be noted that the authors have identified several limitations in the present investigation. First, the presence of a number of demographic variables, including age, personal and executive 
functions, previous academic performance, and the academic rigor of the subject matter may have influenced the results observed in the present investigation. In terms of age, it is estimated that the majority of students who enroll in the Longwood University SLP Online Program are either in the process of completing a bachelor's degree, often in a different major, or already hold a baccalaureate degree in another field. Thus, these students may differ when compared to those who complete CSD undergraduate coursework in a traditional FTF setting. The findings from previous investigations that have explored the effect of age in an online learning format, however, have been mixed. Some research has observed no correlation between age and online learning outcomes (Biner, Summers, Dean, Bink, Anderson, \& Gelder, 1996; Osborn, 2001; Wang \& Newlin, 2002; Willging \& Johnson, 2004), while others have noted that older students perform better academically in comparison to their younger counterparts (Didia \& Hasnat, 1998; Dille \& Mezack, 1991; Willis, 1992; Wojciechowski \& Palmer, 2005). The online success of older students may be augmented by maturation of a number of executive skills believed to be critical to the online learning process, including rehearsal, elaboration, critical thinking, and selfregulation, that come with increases in age (Colorado \& Eberle, 2010). Participant characteristics that appear to be independent of age, including self-discipline and self-directed learning skills, time management skills, and the availability of personal time to devote to the course, may have influenced the outcomes in the present investigation as these have also been extensively identified as critical to success in online learning (Bambara, Harbour, Davies, \& Athey, 2009; Ehrman, 1990; Eisenberg \& Dowsett, 1990; and Liu, Gomez, Khan, \& Yen, 2007).

Online learning may also be influenced by a student's previous academic performance. Figlio, Rush, \& Yin (2010) found no significant differences in the learning outcomes of an economics course, taught online and in a FTF format, amongst students who had earned higher GPAs on previous coursework. However, the investigators found that students who had lower prior GPAs and who were enrolled in this course scored significantly lower on in-class exams in comparison to those who were enrolled in a FTF format. It is possible that students with lower overall GPAs in previous coursework may be disadvantaged in their ability to adapt to an online learning environment when compared to those with higher overall GPAs. Relative to academic rigor, it has been postulated that the ability of a student to adapt to an online learning environment may be influenced by the rigorousness of the academic subject. Some academic subjects may be more conducive to the online learning environment in comparison to others. Jaggars (2012) investigated those subjects that students preferred to take in a FTF format rather than online. The results suggested that academically-challenging coursework, such as mathematics, and those courses deemed unsuitable for the online learning environment, such as laboratory-based science courses, were best taken in a FTF format. Xu and Jaggars (2013) explored online course enrollments across various academic subjects. Of the 14 subject-area categories explored, the authors found that online enrollment was greatest in the arts and humanities courses in comparison to online enrollment in natural science areas.

Other limitations in the present investigation include the influence of previous exposure to course material and individual differences in expressive and receptive language abilities. The investigators did not explore whether some students were repeating the course. The influence of familiarity cannot be discounted and should be explored in future investigations. This pilot study did not ask student participants to complete a screening task of their overall expressive and receptive language abilities. Those with underlying expressive and/or receptive language deficits 
may have demonstrated difficulty understanding the instructions and completing the task successfully due to the interactive nature of language, literacy, and learning. Last, students enrolled in the online course were not given access to a pronunciation portal or recorded lectures as a part of the course materials. It is unknown whether some students may have sought assistance, either before or during the completion of the pronunciation task, from an online pronunciation resource such as The Free Dictionary website (Farlex, Inc., 2019). Students enrolled in the FTF format were frequently exposed to instructor pronunciation of course content as lecture was an integral component of the FTF course.

There are a number of considerations to guide future research. The collection of a variety of student demographic data, including the number of times a student has repeated the human anatomy and physiology course, is clearly indicated in order to provide a more holistic preview of student participants and to determine how these variables may have influenced performance. Future investigations should incorporate a screening of participant expressive and receptive language abilities, with consideration given to whether inclusionary criteria for study participation should be modified based upon a specific, cut-off score.

The findings from this investigation should be used to guide future pedagogical choices when developing an online, science-based course. Previous research has postulated that the use of online technology alone does not necessarily ensure efficacious teaching practices or student mastery of material. However, the findings from this pilot study augment and extend previous work that has suggested a preferential role for a variety of multimedia that includes correct pronunciation of key anatomical terms and multiple opportunities for student engagement and practice. The inclusion of these materials should be further investigated for their utility, ease of use, and effect on pronunciation skills.

\section{Disclosure}

Drs. Cralidis and Salley have no conflicts of interest or financial ties to disclose.

\section{References}

Allen, I. E., \& Seaman, J. (2013). Changing course: Ten years of tracking online education in the United States. Babson Park, MA: Babson Survey Research Group and Quahog Research Group. Retrieved from http://www.onlinelearningsurvey.com/reports/changingcourse.pdf

Bambara, C. S., Harbour, C. P., Davies, T. G., \& Athey, S. (2009). Delicate engagement: The lived experience of community college students enrolled in high-risk online courses. Community College Review, 36(3), 219-238. doi:10.1177/0091552108327187

Biner, P. M., Summers, M., Dean, R. S., Bink, M. L., Anderson, J. L., \& Gelder, B. C. (1996). Student satisfaction with interactive telecourses as a function of demographic variables and prior telecourse experience. Distance Education, 17(1), 33-43. doi:10.1080/0158791960170104

Borsook, T. K., \& Higginbotham-Wheat, N. (1991). Interactivity: What is it and what can it do for computer-based instruction. Educational Technology, 31(10), 11-17. 
Bulger, S. M., Mohr, D. J., \& Walls, R. T. (2002). Stack the deck in favor of your students by using the four aces of effective teaching. The Journal of Effective Teaching, 5(2), 1-8.

Casotti, G., Rieser-Danner, L., \& Knabb, M. T. (2008). Successful implementation of inquirybased physiology laboratories in undergraduate major and nonmajor courses. Advances in Physiology Education, 32, 286-296. doi:10.1152/advan.00100.2007

Chaplin, S. B., \& Manske, J. M. (2005). A theme-based approach to teaching nonmajors biology: Helping students connect biology to their lives. Journal of College Science Teaching, 35(1), 5.

Colorado, J. T., \& Eberle, J. (2010). Student demographics and success in online learning environments. Emporia State Research Studies, 46(1), 4-10.

Cuthrell, K. (2007). Instructional strategies: What do online students prefer. MERLOT Journal of Online Learning and Teaching, 3(4), 357-362.

Didia, D., \& Hasnat, B. (1998). The determinants of performance in the university introductory finance course. Financial Practice and Education, 1(1), 102-107.

Dille, B., \& Mezack, M. (1991). Identifying predictors of high risk among community college telecourse students. American Journal of Distance Education 5(1), 24 - 35. doi:10.1080/08923649109526729

Duffy, J.L., \& Mcdonald, J.B. (2008). Teaching and learning with technology (3rd ed). Boston, MA: Pearson.

Ehrman, M. (1990). Psychological factors and distance education. American Journal of Distance Education, 4(1), 10-23. doi:10.1080/08923649009526688

Eisenberg, E., \& Dowsett, T. (1990). Student drop-out from a distance education project: A new method of analysis. Distance Education, 11(2), 231-253. doi:10.1080/0158791900110205

Figlio, D. N., Rush, M., \& Yin, L. (2010). Is it live or is it internet? Experimental estimates of the effects of online instruction on student learning (NBER Working Paper No. 16089). Cambridge, MA: National Bureau of Economic Research. doi:10.3386/w16089

Gopal, T., Herron, S. S., Mohn, R. S., Hartsell, T., Jawor, J. M., \& Blickenstaff, J. C. (2010). Effect of an interactive web-based instruction in the performance of undergraduate anatomy and physiology lab students. Computers and Education, 55, 500-512. doi:10.1016/j.compedu.2010.02.013

Jaggars, S. S. (2012, April). Beyond flexibility: Why students choose online and face-to-face courses in community college. Paper presented at the American Educational Research Association Annual Meeting, Vancouver, Canada.

Kline, R. B. (2011). Methodology in the social sciences. Principles and practice of structural equation modeling (3rd ed.). New York, NY, US: Guilford Press.

Kuyatt, B. L. \& Baker, J. D. (2014). Human anatomy software use in traditional and online anatomy laboratory classes: Student-perceived learning benefits. Journal of College Science Teaching, 43(5), 14-19.

Limpach, A. L., Bazrafshan, P., Turner, P. D., \& Monaghan, M. S. (2008). Effectiveness of human anatomy education for pharmacy students via the internet. American Journal of Pharmaceutical Education, 72(6), 1-5. doi:10.5688/aj7206145

Liu, S., Gomez, J., Khan, B., \& Yen, C. (2007). Toward a learner-oriented community college online course dropout framework. International Journal on E-Learning, 6(4), 519-542. 
Lowerison, G., Sclater, J., Schmid, R. F., \& Abrami, P. C. (2006). Are we using technology for learning? Journal of Educational Technology Systems, 34(4), 401-425.

Okojie, M. C., Olinzock, A. A., \& Boulder, T. C. O. (2006). The pedagogy of technology integration. The Journal of Technology Studies, 32(2), 66-71. doi:10.21061/jots.v32i2.a.1

Osborn, V. (2001). Identifying at-risk students in videoconferencing and web-based distance education. American Journal of Distance Education, 15(1), 41-54. Retrieved from https://www.learntechlib.org/p/93872/. doi:10.1080/08923640109527073

Perry, J., Kuehn, D., \& Langlois, R. (2007). Teaching anatomy and physiology using computerbased stereoscopic images. Journal of College and Science Teaching, 36(4), 18-23.

Rissing, S. W., \& Cogan, J. G. (2009). Can an inquiry approach improve college student learning in a teaching laboratory? CBE - Life Sciences Education 8(1), 55-61. doi:10.1187/cbe.08-05-0023

Saltarelli, A. J., Roseth, C. J., \& Saltarelli, W. A. (2014). Human cadavers vs. multimedia simulation: A study of student learning in anatomy. Anatomical Sciences Education, 7(5), 331-339. Retrieved from https://doi.org/10.1002/ase.1429. doi:10.1002/ase.1429

Schacter, J. (1999). The impact of education technology on student achievement: What the most current research has to say. Milken Exchange on Education Technology, Santa Monica, CA. Retrieved from https://eric.ed.gov/?id=ED430537

Schneider, R., Morse, D. E., Bennett-Clarke, C., \& Hankin, M. (n.d.). Anatomy and Physiology Revealed 4.0. Retrieved from https://www.mheducation.com/highered/explore/apr/about

Wang, A. Y., \& Newlin, M. H. (2002). Predictors of web-student performance: The role of selfefficacy and reasons for taking an on-line class. Computers in Human Behavior, 18(2), 151-163. doi:10.1016/S0747-5632(01)00042-5

Willging, P. A., \& Johnson, S. D. (2004). Factors that influence students' decision to dropout of online courses. Journal of Asynchronous Learning Network, 8(4), 1-17. doi:10.24059/olj.v13i3.1659

Willis, B. (1992). Effective distance education: A primer for faculty and administrators (Monograph Series in Distance Education, No. 2). Fairbanks: University of Alaska State Wide

Wojciechowski, A., \& Palmer, L. B. (2005). Individual student characteristics: Can any be predictors of success in online classes? Online Journal of Distance Learning Administration 3(2). Retrieved from https://www.researchgate.net/publication /228433849_Individual_student_characteristics_Can_any_be_predictors_of_success_in_ online_classes

Woodrow, J., Mayer-Smith, J. A., \& Pedretti, E. (2000). Assessing technology enhanced instruction: A case study in secondary science. Journal of Educational Computing Research, 23(1), 15-39. doi:10.2190/AX3R-A8T1-H5A3-810H

Xu, D., \& Jaggars, S. S. (2013). Adaptability to online learning: Differences across types of students and academic subject areas (CCRC Working Paper No. 54). Teachers College, Columbia University. 


\section{Appendix}

Twenty key anatomical terms used in this investigation

Larynx

Velar

Diarthrodial

Foramen

Costal

Vomer

Hyoid

Arytenoid

Conchae

Aryepiglottic

Pyriform

Vallecula

Labii

Cuneiform

Platysma

Pterygoid

Alveolar

Sphenoid

Musculus uvula

Arcuate fasciculus 